\title{
Ischemic Neuronal Injury is Ameliorated by Astrocyte Activation
}

\author{
Deon F. Louw, Tetsuya Masada, Garnette R. Sutherland
}

\begin{abstract}
Background: The motivation of this study was to more precisely define the in vivo role of astrocytes in forebrain ischemia. Controversy exists in the literature as to whether they protect or injure neurons in this setting. Methods: Astrocytes in the rat hippocampus were disabled with stereotactic administration of a gliotoxin, ethidium bromide, 3 days prior to induction of forebrain ischemia. The extent of neuronal injury in this group was compared to a control category receiving intrahippocampal saline only. Results: Saline-injected animals demonstrated decreased hippocampal CAl sector injury, and increased gliosis on the side of the injection compared to the contralateral side $(\mathrm{P}<0.01)$ or ethidium bromide-treated animals $(\mathrm{P}<0.05)$. Conclusions: The results suggest that activated astrocytes are protective to neurons subjected to an ischemic insult. This may result from their ability to elaborate neurotrophic factors, buffer potassium and metabolize a variety of neurotransmitters.
\end{abstract}

\begin{abstract}
RÉSUMÉ: Les lésions neuronales ischémiques sont améliorées par l'activation des astrocytes. Introduction: Le but de cette étude était de définir plus précisément le rôle des astrocytes dans l'ischémie du cerveau antérieur in vivo. Il existe une controverse dans la littérature à savoir si les astrocytes protègent ou lèsent les neurones dans ce contexte. Méthodes: Nous avons lésé des astrocytes dans l'hippocampe de rats au moyen de l'administration stéréotaxique d'une gliotoxine, le bromure d'éthidium, 3 jours avant l'induction d'une ischémie du cerveau antérieur. L'étendue des lésions neuronales dans ce groupe a été comparée à celle de contrôles à qui on avait administré du sérum physiologique dans l'hippocampe. Résultats: Les animaux ayant reçu du salin avaient des lésions moins étendues du secteur CAl de l'hippocampe et une gliose plus importante du côté de l'injection comparé au côté opposé $(\mathrm{p}<0.05)$. Conclusions: Ces résultats suggèrent que les astrocytes activés protègent les neurones soumis à une ischémie. Il est possible que ce soit leur capacité d'élaborer des facteurs neurotropes, de tamponner le potassium et de métaboliser différents neurotransmetteurs qui soit responsable de cet effet protecteur.
\end{abstract}

Can. J. Neurol. Sci. 1998; 25: 102-107

The ubiquitous astrocyte has protean physiological roles, and is an essential element in the homeostasis of the normal brain. Astrocytes are thought to buffer potassium and to regulate $\mathrm{pH}$ and osmolality. ${ }^{1.3}$ They are involved in the uptake and metabolism of neurotransmitters, and display a variety of ion channels and receptors. ${ }^{4}$ Glial cells may assist in the control of the microcirculatory blood flow, an activity most likely mediated by nitric oxide. ${ }^{4-6}$ There is also strong evidence to suggest that glutamate-mediated astrocyte-neuron signalling occurs, allowing astrocytes to regulate neuronal calcium levels. ${ }^{7}$ These are merely a sample of the putative or proven tasks of the astrocyte, a generous list of functions that is rapidly expanding.

In contrast to their diverse physiological actions, astrocytes are not commonly the primary substrate of pathology. Hepatic encephalopathy and scrapie are notable exceptions. ${ }^{8.9}$ However, astrocytes are apt to respond energetically to a broad spectrum of neurological insults. ${ }^{9}$ A reactive astrocytosis accompanies cerebral infection, trauma, demyelination and a variety of dementing disorders. ${ }^{10}$ The hypertrophy and/or hyperplasia of astrocytes to stimuli is readily characterized by enhanced glial fibrillary acidic protein (GFAP), and to a lesser extent, vimentin, immunostaining. Those that are vimentin-positive may reflect zones of potentially permanent ischemic injury." The metabolic response of the astrocyte to focal cerebral injury is remarkably rapid, and has been detected within one hour following mechanical trauma. ${ }^{12}$
Although the astrocyte underpins pivotal physiological and pathological functions, its precise role in the genesis of ischemic neuronal injury remains elusive. It might be intuitively suggested that astrocytes, key elements in neurohomeostasis, confer protection on the ischemic neuron. Their ability to siphon away the toxic levels of potassium and glutamate that embalm the ischemic nerve cell implies potential to ameliorate neuronal damage. Nevertheless, it has been proposed that astrocytes may in fact promote neuronal injury under ischemic conditions. Ogata has demonstrated that excitatory amino acids were released in greater amounts from astrocytes than neurons following hypoxic-hypoglycemic stimulation. ${ }^{13}$ He suggests that surrounding astrocytes contribute to the excitotoxic death of ischemic neurons. There is also in vitro evidence that the anion transport inhibitor L-644 711 may reduce brain injury in cerebral ischemia. ${ }^{14}$ It is postulated that this protection, at least in part, is due to the ability of this agent to prevent glutamate release from astrocytes.

From the Department of Clinical Neurosciences, The University of Calgary, Calgary, Canada (D.F.L., G.R.S.); Department of Neurological Surgery and Physiology, Kagawa Medical School, Kagawa, Japan (T.M.).

RECEIVED MARCH 25, 1997. ACCEPTED IN FINAL. FORM SEPTEMBER 5, 1997.

Reprint requests to: Garnette R. Sutherland, Division of Neurosurgery, Department of Clinical Neuroscience, Foothills Medical Centre, 1403 - 29 Street N.W., Calgary, Alberta, Canada T2N 2T9 
It is with this controversy in mind that the present study was undertaken. We planned to investigate the effects of ischemia on neurons following chemical neutralization of their neighbourhood astrocytes, and to compare this to a control group. We designed a novel stroke paradigm whereby gliotoxic lesions were generated in the hippocampus of the rat by stereotactic injection of ethidium bromide. This agent binds to DNA and RNA, disrupting their nucleic acid and protein synthesis. ${ }^{15}$ This injury is limited to glial cells and spares neurons.

\section{Procedures}

\section{Stereotactic Glial Lesioning}

Nineteen male Sprague-Dawley rats were used. Each rat was fasted for 12 hours, pretreated with $0.5 \mathrm{mg} / \mathrm{kg}$ atropine, and then anesthetized with $50 \mathrm{mg} / \mathrm{kg}$ sodium pentobarbital. The animals were placed in a stereotactic frame and coordinates for the CAl sector of the hippocampus selected: $3.8 \mathrm{~mm}$ posterior to the bregma, $2.0 \mathrm{~mm}$ lateral to the midline, and $2.5 \mathrm{~mm}$ below the dura. Nine rats received $1 \mu \mathrm{l}$ of a $0.1 \%$ ethidium bromide solution into the right hippocampus, administered slowly from a 10 $\mu l$ Hamilton syringe and needle. Ten control rats were treated in identical fashion, except for the substitution of normal saline for ethidium bromide. The procedure was well-tolerated, and the animals given three days to recuperate.

\section{Induction of reversible forebrain ischemia}

Three days following stereotactic instillation of either ethidium bromide or normal saline, all rats were anesthetized as described above. The rats were mechanically ventilated and maintained at $37.5^{\circ} \mathrm{C}$ on a heated water blanket placed under both the torso and the head. A temperature electrode inserted through the tympanic membrane monitored cranial temperature prior to, during, and following the ischemic insult. A catheter was inserted into the tail artery of each rat for blood pressure monitoring and blood sampling. Both carotid arteries were exposed through a neck incision. After 20 minutes of stabilization, forebrain ischemia was induced through bilateral carotid occlusion coincident with a reduction in systemic blood pressure to a mean of $50 \mathrm{~mm} \mathrm{Hg}$ through aspiration of blood into a heparinized syringe. After 12 minutes, blood flow through the carotid arteries was restored and the aspirated blood reinfused. Blood gas analyses, glucose levels and hematocrit determinations were obtained both prior to and following the ischemic insult. Ventilatory support was continued until the animal was breathing well and moving its extremities. Rats were returned to their cages and provided with food and water ad lib.

\section{Histopathology}

Seven days after induction of ischemia, each rat was perfusion-fixed with 1 litre of $10 \%$ buffered formaldehyde ( $\mathrm{pH} 7.25$ ). After fixation, the brain was placed in the same fixative for two weeks prior to sectioning. The brains were cut coronally into 1.5 mm slices, dehydrated in graded concentrations of ethanol, and embedded in paraffin. Serial sections $(5 \mu \mathrm{m})$ were cut and stained with haematoxylin and eosin. All sections were examined to determine the qualitative topographic extent of brain damage. For quantification of ischemic neuronal injury, standardized sections of the cerebral cortex, hippocampus, and caudate were used. ${ }^{16-18}$ The hippocampal level corresponding to the needle track was utilized in quantifying CAl neuronal injury and astrocyte activation. The section just posterior to this was used in assessing neocortical injury. The frequency of ischemic neurons was calculated by dividing the number of acidophilia and/or pyknotic neurons by the total number of neurons.

Table 1: Physiological Parameters in Forebrain Ischemia.

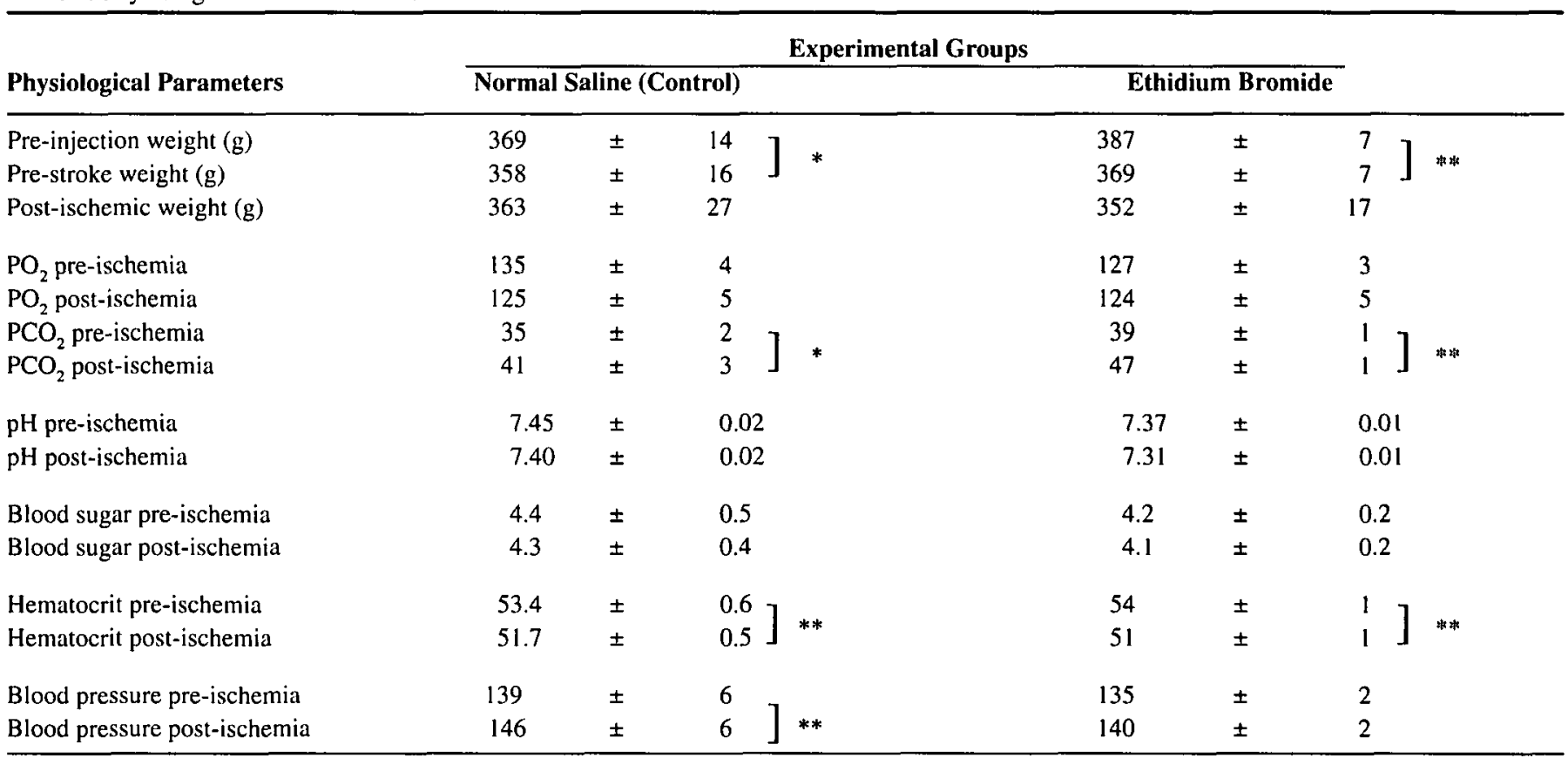

* $\quad P<0.05$

** $\quad \mathrm{P}<0.01$ 

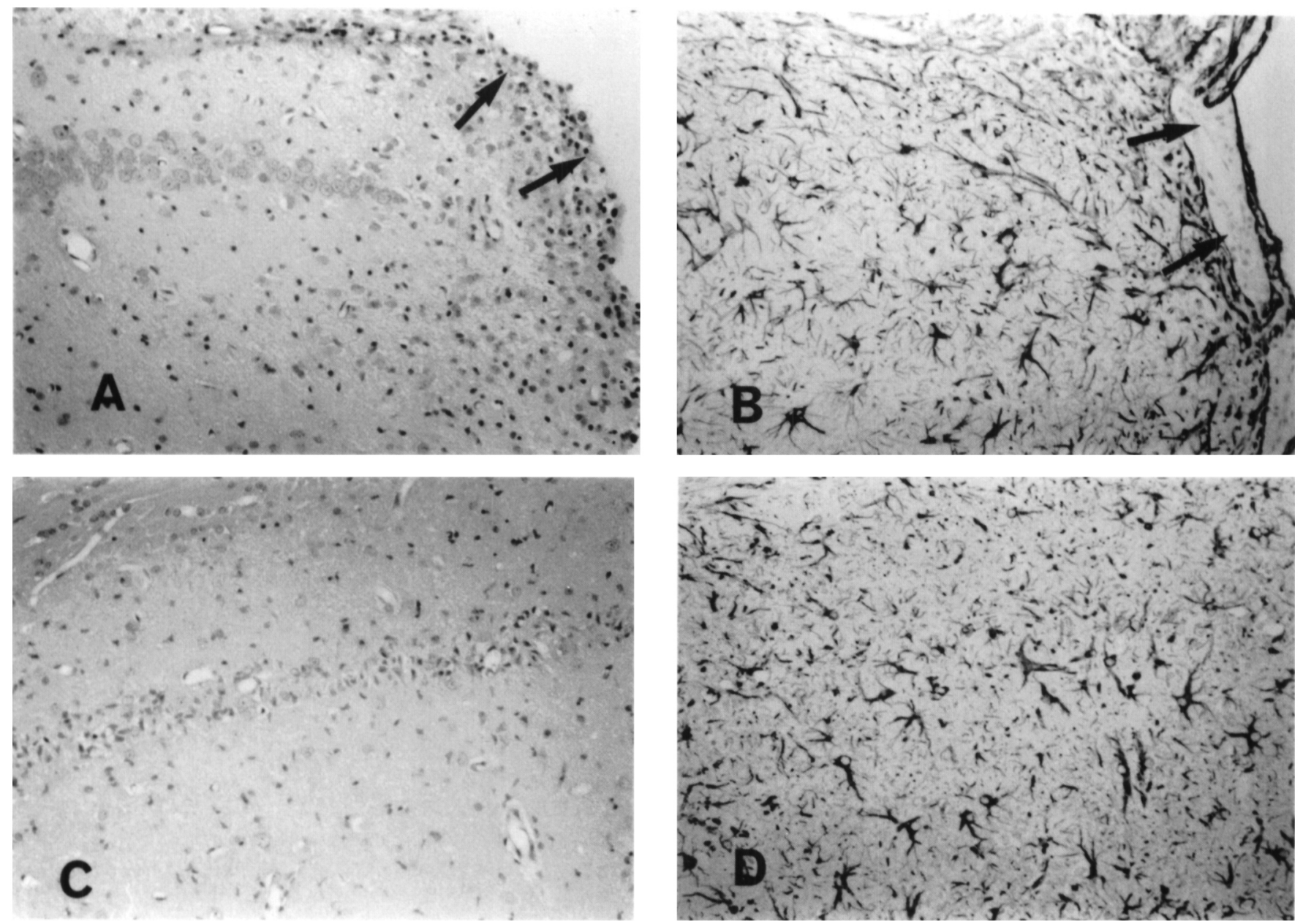

Figure 1: Photomicrographs of hippocampus obtained 10 days following normal saline injection, and 7 days post-forebrain ischemia. A, B: ipsilateral, $C, D$ : contralateral to the injection. Hematoxylinleosin A, C, GFAP B and D stained sections showing localized needle track injury (arrows in $A$

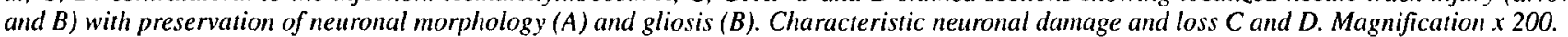

\section{Immunochemistry (GFAP)}

Formalin-fixed, paraffin-embedded sections of $3 \mu \mathrm{m}$ were picked up onto amino-alkyl-silane coated slides, air dried in a $37^{\circ} \mathrm{C}$ incubator/hot air oven for 2-18 hours. Deparaffinized sections were incubated in $3.0 \% \mathrm{H}_{2} \mathrm{O}_{2} /$ methanol for $20 \mathrm{~min}$ utes to block endogenous peroxidase activity and then subjected to proteolytic enzyme digestion using $0.1 \mathrm{~g}$ trypsin $/ 100 \mathrm{ml}$ $2.0 \% \mathrm{CaCl}_{2}(\mathrm{pH} 7.4-7.6)$ for 30 minutes at $37^{\circ} \mathrm{C}$. Sections were blocked in normal goat serum and then incubated in rabbit anti-cow glial fibrillary acidic protein 1/500 (Dakopatts Z 334) for 60 minutes, washed with buffer; followed by biotinylated goat anti-rabbit IgG (Sigma EXTRA-3) for 30 minutes, washed with buffer; then incubated with streptavidin peroxidase (Sigma EXTRA-3) for 30 minutes. Signal production was generated using (DAB) diaminobenzidine tetrahydrochloride (Sigma D5736). ${ }^{19.20}$ Astrocytic quantification for the CAl sector was determined by dividing the number of reactive astrocytes by the area.

\section{Statistics}

All data are presented as mean \pm SEM. Comparisons between the groups were performed utilizing a one way ANOVA.

\section{Results}

\section{Physiological Data}

Physiological data are presented in Table 1. There were no significant differences between the groups for any of the parameters. The stereotactic injection was followed by a significant reduction in body weight. The ischemic insult was associated with a mild metabolic acidosis, hemodilution, and increased systemic blood pressure.

\section{Histopathology}

\section{(a) Qualitative Findings}

Figure 1 shows photomicrographs obtained 7-days postischemia from a normal saline-treated animal, hematoxylin and eosin (A, C), GFAP (B, D). The injection of normal saline 3 days prior to ischemia into the hippocampal CAl sector (A, B) was associated with localized gliosis and decreased ischemic neuronal injury compared to the contralateral side $(C, D)$. Ischemic neurons were characterized by retraction of the cell body, eosinophilia of the cytoplasm, disappearance of Nissl bodies, and pyknosis/hyperchromasia of the nucleus. Figure 2 shows photomicrographs obtained 7-days post-ischemia from an animal treated with ethidium bromide 3 days prior to ischemia. 

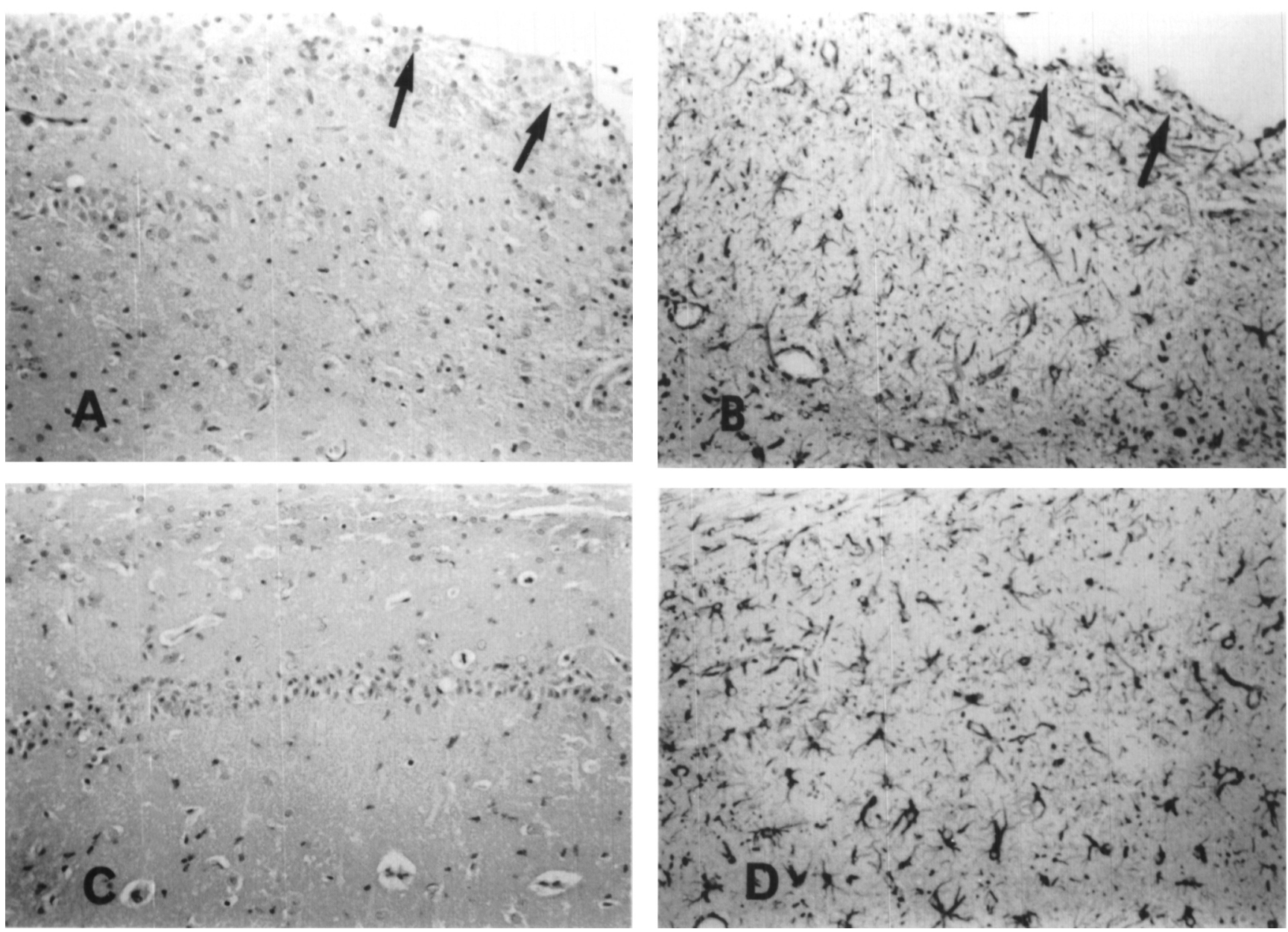

Figure 2: Photomicrographs of hippocampus obtained 10 days following ethidium bromide injection and 7 days post-forebrain ischemia. A, B: ipsilateral, $C, D$ : contralateral to the injection. Hematoxylin/eosin A, C, GFAP B and D stained sections showing localized needle track injury (arrows in $A$ and $B$ ) with characteristic neuronal damage and loss on both the ipsilateral and contralateral sides. Magnification $\times 200$.

Within the CAl sector, the degree of localized gliosis was less compared to normal saline-injected animals, and the severity of ischemic neuronal injury was similar to the contralateral side.

Neocortical injury was symmetric and restricted to mid-neocortical layers and was most severe in the watershed zone between the territory of supply of the anterior and middle cerebral arteries, tapering posteriorly as the territory of the posterior cerebral artery was approached. Striatal injury involved primarily small and medium-sized neurons located in the dorsal-lateral portion.

\section{(b) Quantitative Findings}

Total cell counts for the regions examined did not differ between groups. Ischemic neuronal injury in the examined regions is presented in Tables 2 and 3. Within the hippocampal CAl sector (Table 2), normal saline-injected animals showed significantly less damage ipsilateral to the injection compared to the contralateral side $(P<0.01)$ or ethidium bromide group $(P<$ 0.05 ). In the normal saline group the injected side showed a significantly greater number of reactive astrocytes $/ \mathrm{mm}^{2}$ compared to the contralateral side and ethidium bromide group $(\mathrm{P}<0.01)$. Within the ethidium bromide group, the number of reactive astro- cytes $/ \mathrm{mm}^{2}$ was less on the side of injection. Striatal injury was also significantly less within the normal saline-injected group on the side ipsilateral to the injection $(\mathrm{P}<0.05)$. There were no other significant differences within or between the groups.

\section{Discussion}

The only experimental difference between the two groups is that the anticipated hippocampal and striatal gliosis of the stab injury was blocked by the administration of a gliotoxin in nine animals. It is reasonable then to deduce that the protection seen in the control (saline) group was afforded by uninhibited astrocytosis. Our study offers good evidence that in the in vivo situation astrocytes shield neurons from ischemic injury, suggesting that the in vitro data of astrocyte culpability are not readily applicable to the clinical model. ${ }^{13.14}$ It appears to be a case where more is better, as the control group astrocytes are not only functioning but in fact have been activated by pre-emptive lesioning. We wish to emphasize that our contention that astrocytes salvage ischemic neurons is based on the presence of strict normoglycemic conditions. Walz has demonstrated that simulation of hyperglycemic ischemia results in an almost sevenfold 
Table 2: Quantitative Histopathology - Hippocampus.

\begin{tabular}{|c|c|c|c|c|c|c|c|c|c|c|c|c|c|}
\hline \multirow{2}{*}{$\begin{array}{l}\text { Hippocampal } \\
\text { sector } \\
\mathrm{CA} 1\end{array}$} & \multicolumn{4}{|c|}{ Ipsilateral } & \multicolumn{3}{|c|}{ Contralateral } & \multicolumn{3}{|c|}{ Ipsilateral } & \multicolumn{3}{|c|}{ Contralateral } \\
\hline & & & & & & & & & & & & & \\
\hline - Neurons & 41 & \pm & 11 & $* \uparrow$ & 83 & \pm & 4 & 76 & \pm & 10 & 78 & \pm & 11 \\
\hline - Glia & 163 & \pm & 17 & $* \dagger \dagger$ & 125 & \pm & 4 & 109 & \pm & 21 & 124 & \pm & 6 \\
\hline CA $2 / 3$ & 19 & \pm & 9 & & 11 & \pm & 2 & 24 & \pm & 11 & 13 & \pm & 8 \\
\hline $\mathrm{CA} 4$ & 49 & \pm & 6 & & 4 & \pm & 5 & 14 & \pm & 7 & 12 & \pm & 7 \\
\hline
\end{tabular}

Results expressed as Mean \pm SE.

Neuronal counts are expressed as a \% of ischemic neurons / total neurons. Glial cell quantification is presented as number of astrocytes $/ \mathrm{mm}^{2}$.

$* \mathrm{P}<0.01$ compared to contralateral side.

$\dagger \mathrm{P}<0.05$ compared to ethidium bromide group.

$\dagger \dagger \mathrm{P}<0.01$ compared to ethidium bromide group.

Table 3: Quantitative Histopathology - Striatum and Neocortex.

\begin{tabular}{|c|c|c|c|c|c|c|c|c|c|c|}
\hline \multirow{3}{*}{$\frac{\text { Brain Region }}{\text { Striatum }}$} & \multicolumn{4}{|c|}{ Normal Saline $(n=10)$} & \multicolumn{6}{|c|}{ Ethidium Bromide $(n=9)$} \\
\hline & \multicolumn{2}{|c|}{ Ipsilateral } & \multicolumn{2}{|c|}{ Contralateral } & \multicolumn{3}{|c|}{ Ipsilateral } & \multicolumn{3}{|c|}{ Contralateral } \\
\hline & 93 & $34 \ddagger$ & 185 & 39 & 143 & \pm & 37 & 130 & \pm & 44 \\
\hline
\end{tabular}

Results expressed as Mean \pm SE.

$\ddagger \mathrm{P}<0.05$ compared to contralateral sides.

Striatal and neocortical injury is presented as total number of ischemic neurons observed in standardized sections. Three $1 \mathrm{~mm} x 1 \mathrm{~mm}$ regions in each dorsal lateral striatum and four $1 \mathrm{~mm} \times 1 \mathrm{~mm}$ regions in each neocortex.

increase in lactate release, $92 \%$ of which is accounted for by astrocytes. ${ }^{2,3}$ This provokes an extremely acidic environment ${ }^{21}$ and could potentially aggravate disruption of $\mathrm{pH}$-sensitive enzyme systems.

An alternative explanation of the increased injury in the ethidium bromide group is that this agent acquires neurotoxic properties under ischemic conditions, and that it is the absence of this drug rather than the unrestrained gliosis seen in the saline group, that is protective. We are unaware, however, of any experimental evidence suggesting that ethidium bromide is toxic to ischemic neurons. The ethidium bromide injures oligodendrocytes as well as astrocytes and induces demyelination. ${ }^{15}$ This demyelination may be accompanied by the release of lysosomal enzymes and proteinases from activated macrophages and could possibly be injurious to compromised neurons. ${ }^{15,22}$ Furthermore, the administration of ethidium bromide may alter the ratio between astrocytes and microglia in the traumatized brain. Astrocytes are generally not thought to be mobile, and it is possible that microglia advance into the injury zone in the hippocampus as the ethidium bromide concentration and toxicity wane. Giulian has revealed that these cell types are rivals in controlling neuronal survival. ${ }^{23} \mathrm{He}$ has demonstrated that reactive microglia secrete neurotoxic agents and that astroglia elaborate neurotrophic substances. Despite these theoretical considerations, the significant salvage of neurons we noted in the saline-injected hippocampi in relation to their contralateral hemispheres, strongly implicates an ameliorative role for astrocytes in ischemic injury.
The most likely candidates as neuroprotective agents are the trophic factors secreted by astrocytes. Neito-Sampedro has shown that focal cerebral injury provokes a time-dependent increase in neuronotrophic activity at the site of the lesion. ${ }^{24}$ Trophic activity was highest in developing animals, and was substantially elevated within three days of brain injury. A study of reactive astrocytes indicates that they generate nerve growth factor (NGF), basic fibroblast growth factor (bFGF) as well as insulin-like growth factor-1 (IGF-1). In vitro studies suggest that these factors protect neurons from hypoglycemic challenges by stabilizing calcium homeostasis in neurons. ${ }^{9.25}$ In vivo experimentation with bFGF pretreatment in focal cerebral ischemia reduces infarct size. ${ }^{26}$ bFGF protects neurons from excitotoxic amino acids, and may influence neuronal transcription and translation. ${ }^{27} \mathrm{Glial}$ cells, endothelial cells and blood vessels proliferate in response to bFGF, ${ }^{6.28}$ possibly enhancing collateral blood flow. ${ }^{26}$

Reactive astrocytes undergo a formidable metabolic mobilization. In addition to the changes mentioned above, they also express gamma aminobutyric acid (GABA) immunoreactivity. ${ }^{29}$ The time course of induction of GABA reactivity is correlated with that for GFAP, and occurs in ischemic forebrain structures. This could reflect intrinsic synthesis, or alternatively, uptake of GABA elaborated by neurons. ${ }^{30}$ Reactive astrocytes upregulate their glutamine synthetase levels, enhancing their capacity to metabolise glutamate to glutamine..$^{9,31}$ Mitochondria in astrocytes increase in number within three hours of an ischemic 
insult. ${ }^{32}$ Stimulation of the aforementioned enzyme systems and organelles should buttress the neuron against ischemia.

In conclusion, we have presented a novel method of examining gliotoxicity in stroke, and suggest that forebrain ischemia in the presence of activated astrocytes is less harmful to neurons. However, we need to emphasize that our interpretation of these preliminary results, and their potential application to future research, remain speculative and phenomenologically based. Important questions that remain include the relevance of our hypothesis to focal ischemia, and whether unactivated or "quiescent" astrocytes are as protective as their activated counterparts. Concern is also raised about the pragmatic issue of astrocyte activation in the stroke patient, and how this may be safely accomplished. In addition, the potential toxicity of ethidium bromide probably precludes its application in a human paradigm. Future directions include the investigation of vulnerability to ischemia in pathological conditions of glial dysfunction, such as hepatic encephalopathy. Strategies of salvage in stroke should include optimization of astrocyte function, and not be limited to the neuron.

\section{ACKNOWLEDGEMENTS}

This study was supported by a grant from the Heart and Stroke Foundation of Alberta. The authors acknowledge the technical support provided by M. Tanaka and F.-W. Yang, and Maureen Firmston for preparation of the manuscript.

\section{REFERENCES}

1. Swanson RA. Astrocyte glutamate uptake during chemical hypoxia in vitro. Neurosci Lett 1992; 147: 143-146.

2. Walz W. Role of glial cells in the regulation of the brain microenvironment. Prog Neurobiol 1989; 33: 309-333.

3. Walz W, Mukerji S. Simulation of aspects of ischemia in cell culture: changes in lactate compartmentation. Glia 1990; 3: 522528.

4. Barres BA. New roles for glia. J Neurosci 1991; 11: 3685-3694.

5. Murphy S, Minor RL, Welk G, Harrison DG. Evidence for an astrocyte-derived vasorelaxing factor with properties similar to nitric oxide. J Neurochem 1990; $55: 349-351$

6. Newman EA, Frambach DA, Odette LL. Control of extracellular potassium levels by retinal glial cell K siphoning. Science 1984; 225: 1174-1175.

7. Parpura V, Basarsky TA, Liv F, et al. Glutamate-mediated astrocyte-neuron signalling. Nature 1994; 369: 744-747.

8. Diedrich JF, Bendheim PE, Kim YS, et al. Scrapie-associated prion protein accumulates in astrocytes during scrapie infection. Proc Nat Acad Sci U.S.A. 1991; 88: 375-379.

9. Eddelstone M, Mucke L. Molecular profile of reactive astrocytes implications for their role in neurologic disease. Neuroscience 1993; 54: 15-36.

10. De Le Monte SM, Ho DD, Schooley RT, et al. Subacute encephalomyelitis of AIDS and its relation to the HTLV-III infection. Neurology 1987; 37: 562-569.

11. Petito CK, Morgello S, Felix JC, Lesser ML. The two patterns of reactive astrocytosis in post ischemic rat brain. J Cereb Blood Flow Metab 1990; 10: 850-859.

12. Mucke L, Oldstone MBA, Morris JC, Nerenberg MI. Rapid activation of astrocyte-specific expression of GFAP-lacZ transgene by focal injury. New Biol 1991; 3: 465-474.
13. Ogata T, Nakamura Y, Shibata T, Kataoka K. Release of excitatory aminoacids from cultured hippocampal astrocytes induced by a hypoxic-hypoglycemic stimulation. J Neurochem 1992; 58: 1957-1959.

14. Bednar NN, Kohut JJ, Kimelberg HK, et al. In vitro evidence supporting two mechanisms of action for the anion transport inhibitor L-644,711 in cerebral ischemia. Neurol Res 1992; 14: 53-56.

15. Blakemore WF. Ethidium bromide induced demyelination in the spinal cord of the cat. Neuropathol Appl Neurobiol 1982; 8: 365375.

16. Luvisotto TL, Auer RN, Sutherland GR. The effect of mannitol on experimental cerebral ischemia, revisited. Neurosurgery 1996; 38: $131-139$

17. Sutherland GR, Peeling J, Lesiuk HJ, et al. The effects of caffeine on ischemic neuronal injury as determined by magnetic resonance imaging and histopathology. Neuroscience 1991; 42: 171 . 182.

18. Sutherland G, Lesiuk H, Bose R, Sima AAF. Effect of mannitol, nimodipime, and indomethacin singly or in combination on cerebral ischemia in rats. Stroke 1988; 19: 571-578.

19. Hsu SM. The use of avidin-biotin-peroxidase complex $(A B C)$ in immunoperoxidase techniques. $A$ comparison between $A B C$ and unlabelled antibody PAP procedures. J Histochem Cytochem 1981; 29: 577-580.

20. Sternberger LA. The unlabelled antibody enzyme method of immunohistochemistry. J Histochem Cytochem 1970; 13: 315333.

21. Kraig KP, Chesler M. Astrocytic acidosis in hyperglycemic and complete ischemia. J Cereb Blood Flow Metab 1990; 10: 104. 114.

22. Norten WT, Cammer W, Bloom BR, Gordon S. Neutral proteinases secreted by macrophages degrade basic protein: a possible mechanism of inflammatory demyelination. In: Palo J, ed. Myelination and Demyelination. New York: Plenum Press, 1978 365-381.

23. Guilian D. Reactive glia as rivals in regulating neuronal survival. Glia 1993; 7: 102-110.

24. Nieto-Sampedro, Lewis ER, Cotman CW, et al. Brain injury causes a time-dependent increase in neurotrophic activity at the lesion site. Science 1982; 217: 860-861.

25. Cheng B, Mattson MP. NGF and bFGF protect rat hippocampal and human cortical neurons against hypoglycemic damage by stabilising calcium homeostasis. Neuron 1991; 7: 1031-1041.

26. Koketsu N, Berlove DJ, Moskowitz MA, et al. Pretreatment with intraventricular basic fibroblast growth factor decreases infarct size following focal cerebral ischemia in rats. Ann Neurol 1994; 35: 451-457.

27. Mattson MP, Murrain M. Guthrie PB, Kater SB. Fibroblast growth factor and glutamate: opposing roles in the generation and degeneration of hippocampal neuroarchitecture. J Neurosci 1989; 9: 3728-3740.

28. Pettman B, Weibel M, Sensenbrenner M, Labourdette G. Purification of two astroglial growth factors from bovine brain. FEBS Lett 1985; 189: 102-108.

29. Lin RCS, Polsky K, Matesic DF. Expression of $\gamma$-aminobutyric acid immunoreactivity in reactive astrocytes after ischemia-induced injury in the adult forebrain. Brain Res 1993; 600: 1-8.

30. Sutherland GR, Bose R, Louw D, Pinsky C. Global elevation of brain superoxide dismutase activity following forebrain ischemia in rat. Neurosci Lett 1991; 128: 169-172.

31. Norenberg MD. Immunohistochemistry of glutamine synthetase. In: Hertz L, ed. Glutamine, Glutamate, and GABA in the Central Nervous System. New York: A.R. Liss, 1983: 95-111.

32. Petito CK, Babiak T. Early proliferative changes in astrocytes in postischemic noninfarcted rat brain. Ann Neurol 1982; 11:510518. 